\title{
Using the cultural model to plan intervention for malaria control in immigrants and native communities in endemic area, earmarked for malaria elimination southeastern Iran
}

\author{
Khandan Shahandeh ${ }^{1,2^{*}}$, HamidReza Basseri ${ }^{3}$, Esmaeil Shojaeizadeh ${ }^{4}$ \\ From Challenges in malaria research \\ Basel, Switzerland. 10-12 October 2012
}

\section{Background}

To improve malaria control measures, taking into account local beliefs and practices are essential. Recently, Iran has been earmarked for malaria elimination while the majority of malaria patients are imported cases from eastern neighbouring countries.

In the present study, we employed the culture model as a theoretical framework to examine how health beliefs, behaviors and practices associated with improving access to prevention measures, early diagnosis and treatment of malaria in two communities, immigrants and native residents in a malaria endemic region located in southeast of Iran.

\section{Materials and methods}

A mixed-methodology was designed by means of two quantitative surveys and qualitative focus groups. In total, 380 participants volunteered to take the cross-sectional survey, with 185 immigrants, 195 native residents completing quantitative surveys and also 40 participating in the qualitative focus groups.

\section{Results}

A significant association between education level and knowledge on malaria transmission was also observed within both communities. Although the majority respondents associated the disease transmission with mosquito bites only $16.5 \%$ immigrants as compared to $63.4 \%$ native residents reported to use mosquito net. Data from focus group emerged three themes includes similarity in

'Department of Health Education and Promotion, School of Public Health,

Tehran University of Medical Sciences, Tehran, Iran

Full list of author information is available at the end of the article perception about malaria, difference in type of treatment and decision making and, finally resemblance to prevention of malaria in both communities.

\section{Conclusions}

Matching the cultural characteristics of immigrants and native residents' culture to malaria interventions and services will improve receptivity to, acceptance of, and salience of these efforts.

\section{Author details}

'Department of Health Education and Promotion, School of Public Health, Tehran University of Medical Sciences, Tehran, Iran. ${ }^{2}$ Center for Community Based Participatory Research. Tehran University of Medical Sciences, Tehran, Iran. ${ }^{3}$ Department of Medical Entomology \& Vector Control, School of Public Health, Tehran University of Medical Sciences, Tehran, Iran. ${ }^{4}$ School of Public Health, Tehran University of Medical Sciences, Tehran, Iran.

Published: 15 October 2012

\section{References}

1. Onwujekwe O, Uzochukwu B, Dike N, Okoli C, Eze S, Chukwuogo O: Are there geographic and socio-economic differences in incidence, burden and prevention of malaria? A study in southeast Nigeria. Int J Equity Health 2009, 8:45.

2. Airhihenbuwa CO: Of Culture and Multiverse: Renouncing the 'Universal Truth' in Health. Journal of Health Education 1999, 30:267-273.

3. Airhihenbuwa CO: Healing our differences: The crisis of global health and the politics of identity. New York: Rowman and Littlefield; 2007.

4. Basseri H, Raeisi A, Ranjbar Khakha M, Pakarai A, Abdolghafar H: Seasonal abundance and host-feeding patterns of anopheline vectors in malaria endemic area of iran. J Parasitol Res 2010, 2010:671291.

5. Basseri HR, Raeisi A, Holakouie K, Shahandeh K: Malaria prevention among Afghani refugees in a malarious area, southeastern Iran. Bull Soc Pathol Exot 2010, 103(5):340-345.

6. Martens $P$, Hall L: Malaria on the move: human population movement and malaria transmission. Emerg Infect Dis 2000, 6(2):103-109. 
7. Tatem AJ, Smith DL: International population movements and regional Plasmodium falciparum malaria elimination strategies. Proc Natl Acad Sci U S A 2010, 107(27):12222-12227.

doi:10.1186/1475-2875-11-S1-P132

Cite this article as: Shahandeh et al.: Using the cultural model to plan intervention for malaria control in immigrants and native communities in endemic area, earmarked for malaria elimination southeastern Iran. Malaria Journal 2012 11(Suppl 1):P132.

Submit your next manuscript to BioMed Central and take full advantage of:

- Convenient online submission

- Thorough peer review

- No space constraints or color figure charges

- Immediate publication on acceptance

- Inclusion in PubMed, CAS, Scopus and Google Scholar

- Research which is freely available for redistribution

Submit your manuscript at www.biomedcentral.com/submit
() Biomed Central 